\title{
RUMOR COMMUNITIES, SOCIAL MEDIA, AND FORTHCOMING INNOVATIONS: THE SHAPING OF TECHNOLOGICAL FRAMES IN PRODUCT MARKET EVOLUTION
}

\author{
Victor P. Seidel \\ Babson College \& Said Business School, University of Oxford \\ vseidel@babson.edu / victor.seidel@sbs.ox.ac.uk \\ Timothy R. Hannigan \\ University of Alberta \\ tim.hannigan@ualberta.ca \\ Nelson Phillips \\ Imperial College London \\ n.phillips@imperial.ac.uk
}

October 2018 accepted version pre-publication version for Academy of Management Review

Later published as: Seidel, V.P., Hannigan, T.R., Phillips, N. (2020). Rumor communities, social media, and forthcoming innovations: The shaping of technological frames in product market evolution. Academy of Management Review. Vol: 45, Issue: 2, Page: 304-324

Acknowledgements: The authors would like to acknowledge helpful comments on earlier versions of this paper from Stine Grodal and Tom Lawrence, along with feedback from seminar participants at ETH Zurich and from contributors to the University of Alberta Strategic Management and Organization Paper Development Workshop. We also thank associate editor Mike Pfarrer and three anonymous reviewers for providing exceptional comments and encouragement that guided the final result. We also acknowledge funding and support from the Oxford University Centre for Corporate Reputation. 


\title{
RUMOR COMMUNITIES, SOCIAL MEDIA, AND FORTHCOMING INNOVATIONS: THE SHAPING OF TECHNOLOGICAL FRAMES IN PRODUCT MARKET EVOLUTION
}

\begin{abstract}
Technological frames provide an interpretive mechanism for individuals to evaluate new product innovations. These frames therefore play an important role in product market evolution. But how are technological frames themselves shaped? Prior research has demonstrated how technological frames are influenced by consumers' direct experience with new products and are informed by traditional media evaluations. More recently, however, the emergence of social media has resulted in the development of new arenas where consumers, producers, and other actors discuss and debate forthcoming product innovations by exchanging rumors and propositions. Integrating insights from the sociology of rumor and the affordances of social media, we propose a model of how online product rumor communities shape technological frames in a way not accounted for by prior models of innovation and product market evolution. Online product rumor communities influence product market evolution not only when products are released but also in the "prehistory" of product markets.
\end{abstract}

Keywords: Product innovation; online communities; social media; technological frames; sociology of rumor 
In late 2009, prior to the much-anticipated formal introduction of Apple's entry into the emerging "tablet computer market," rumors around the forthcoming Apple product were so extensive that a social media technology blog called Gizmodo felt it necessary to put together an "Exhaustive Guide to Apple Tablet Rumors" (Bilton, 2009). At this time, social media platforms consisting of multiple technology blogs and online forums featured wide ranging discussions among diverse and distributed individuals about product rumors related to this much anticipated forthcoming product —including debates over product features, possible competitors, probable uses, and release dates. Together, this discussion helped to frame expectations and emergent interpretations of not only the forthcoming "tablet" from Apple but also the nascent evolution of the tablet product market more generally. And these discussions did not go unnoticed within Apple. A Senior Vice President later discussed how they followed such technology blogs, telling one tech blogger, "We talk about this too. The same things you guys talk about, we talk about internally all the time" (DaringFireball, 2015).

In the above illustration, social media provided an arena by which dispersed individuals—-such as bloggers, consumers, and industry staff—could discuss and debate anticipated forthcoming products by exchanging rumors and propositions as part of an online product rumor community. Through such rumor communities, individuals shape "technological frames" (Orlikowski \& Gash, 1994) related to an evolving product market—such as in the case above, where the rumor community framed interpretations of the emerging "tablet computer" market. At the same time, individuals draw on technological frames to evaluate both forthcoming products and products released within a market. In this paper, we will describe how online product rumor communities provide the means to shape technological frames in a way not accounted for by prior models of product market evolution. 
A central concern of theories of product market evolution is how products are developed and adopted through various socio-cognitive mechanisms. One key mechanism driving product adoption is how individuals draw upon technological frames to interpret and make sense of new products (Orlikowski \& Gash, 1994). A technological frame guides the "interpretation of what a technology is and whether it does anything useful" (Kaplan \& Tripsas, 2008: 791). As such, a technological frame provides cues for categorizing a product and for the appropriate performance criteria to be used to assess its use (Benner \& Tripsas, 2012). Technological frames thereby guide interpretations among producers, consumers, and other institutional actors for how and whether they might adopt a new technological product, influencing the dynamics of product market evolution.

Prior research has demonstrated how technological frames are shaped by consumers' direct experience with new products combined with information drawn from media evaluations of products and markets (Kaplan \& Tripsas, 2008; Kennedy, 2008; Khaire \& Wadhwani, 2010; Rosa, Porac, Runser-Spanjol, \& Saxon, 1999). For example, during the early evolution of the “minivan" market, the categorization of different body styles was uncertain (Rosa et al., 1999), with some vehicles reflecting more "car-like" and others more "truck-like" interpretations and associated frames. Not until consumers had direct experience with different vehicles, combined with media evaluations of offerings, did a consensus take shape on what constituted the emergent minivan market and its associated technological frames.

While direct experience and media evaluations remain important in shaping technological frames, the emergence of social media provides a new arena for such activity. Social media, when compared with traditional media, is characterized by wide access, anonymity, immediacy, interdependence, and permanence on multiple platforms (Leonardi \& Vaast, 2017; Seong, 2017; 
McFarland \& Ployhart, 2015), and these characteristics make social media a prime candidate for the development and transmission of rumors (Oh, Agrawal, \& Rao, 2013). Through social media, individuals can not only exchange news about products already introduced but also easily share product rumors and provide further propositions about forthcoming products. Product rumorspropositions about the attributes of a forthcoming product based on uncertain evidence (Fine \& DiFonzo, 2011) — can be easily exchanged via social media within online product rumor communities.

Our objective is to develop a theory to explain how the use of social media provides a means by which online product rumor communities - defined as collectives of individuals who exchange propositions about forthcoming products on social media—can shape technological frames during product market evolution. A focus on online product rumor communities allows us to understand how collective sensemaking may take place not only after product introduction but also before the physical product is introduced (Muniz, O'Guinn, \& Fine, 2006), in the "prehistory" of products and markets (Kirsch, Moeen, \& Wadhwani, 2014; Grodal, Gotsopoulos, \& Suarez, 2015; Suarez, Grodal, \& Gotsopoulos, 2015). The existence of an online product rumor community—a form of "rumor community" more generally (Edy \& Risley-Baird, 2016) —is increasingly common across many product markets. However, the role of online product rumor communities in shaping technological frames within product market evolution has not yet been thoroughly examined by researchers, which may lead to an incomplete understanding of how technological frames are formed, contested, and updated in product markets mediated by social media. By focusing on the role of online product rumor communities in the context of technological frames, we provide the means to guide future empirical work on the shaping of technological frames during product market evolution. 


\section{TECHNOLOGICAL FRAMES IN PRODUCT MARKET EVOLUTION}

Studies of product market evolution have largely focused on how new products are introduced into a market, experienced by consumers, and subsequently adopted or discarded (e.g. Nelson \& Winter, 1982; Clark, 1985; Kaplan \& Tripsas, 2008). While much research focuses on how novel products are adopted (Rindova \& Petkova, 2007), ongoing product innovation also includes extensive incremental innovation (Clark, 1985). Both the introduction of novel and more incremental innovations make up the ongoing evolution of a product market (Abernathy \& Clark, 1985; Clark, 1985; Kaplan \& Tripsas, 2008).

For example, the evolution of passenger cars has included both incremental innovations, such as gradual improvements in the braking systems of existing vehicle models, and more novel innovations, such as the development of the hybrid vehicles that have subsequently come to define a new product category. While highly novel product introductions are more challenging for product adoption, any new product faces some level of ambiguity, as different "actorsproducers, users or institutions - are unsure about what it is or how it will perform" (Kaplan \& Tripsas, 2008: 790). One way in which actors make sense of the direction of product market evolution is to draw on technological frames.

Technological frames are the set of assumptions by which individuals interpret product features and the potential use of a technology, and they also reflect how a technology is categorized and what are considered relevant performance criteria (Orlikowski \& Gash, 1994; Kaplan \& Tripsas, 2008). Different individuals can hold disparate views of a technology’s purpose, and consequently identical technological products can be viewed in different ways depending on their framing (Pinch \& Bijker, 1984). Conversely, when technological frames are 
shared more widely, they can provide common interpretations to inform broader collective action (Tushman \& Rosenkopf, 1992: Weick, Sutcliffe, \& Obstfeld, 2005).

As such, technological frames serve as a cognitive basis for sensemaking (Weick, 1995), as individuals have expectations that are cued when a frame is activated (Tannen, 1979). In this way, "frames can be thought of as hypotheses about the sorts of events that may be encountered in a given scenario" (Cornelissen \& Werner, 2014: 188). The activation of different technological frames can therefore help or hinder product adoption. For example, a new product may have design cues that draw from frames related to prior technologies — such as electric light fixtures drawing upon prior gas fixtures_- so that consumers are afforded an easy interpretation of its function when they first experience it, facilitating quick adoption (Hargadon \& Douglas, 2001; Clark, 1985; Kaplan \& Tripsas, 2008).

Once a technological frame is activated, it becomes a point of reference that focuses attention, interpretation, and experience for actors to make inferences in action (Benner \& Tripsas, 2012). A technological frame can further be thought of as a form of tacit knowledge structure (Weick, 1995) that enables the enactment of a product market by consumers and producers, and "for product markets to exist, the cognitive structures underlying the market must be stable across time, extended across space, and shared by many actors on both sides of the market" (Rosa et al., 1999: 68). In summary, past work has demonstrated that technological frames are fundamental to guiding the evolution of product markets.

The importance of technological frames in product market evolution leads to a question: where and how are technological frames shaped? In existing models, frames are shaped in the interactions among producers, consumers, and traditional media. Two related loci of interaction have been identified as being particularly important in shaping technological frames. The first 
locus is between consumers and physical products, where frames are shaped by the direct experience of consumers interacting with products within a market. Consumers have concepts they have accumulated through their prior experiences with existing products, and these existing concepts frame their initial understanding of new products (Clark, 1985), which are then updated as they test and refine their understandings through direct experience.

For example, in the early personal digital assistant (PDA) market, some new products drew upon themes from earlier word processing products, helping consumers draw on familiar frames to understand the capabilities of the new PDA product (Kaplan \& Tripsas, 2008), but it was only in their direct experience with competing products that a technological frame for a PDA emerged. As consumers shared their experiences, they engaged in a "discursive discovery procedure" (Hayak, 1978), a form of collective sensemaking (Weick, 1995) about how new products fit with ongoing product evolution and how to appropriately frame an understanding of them. In summary, direct experience with new products is a primary mechanism for forming an understanding of the product that guides its adoption (Grodal et al., 2015), and, in turn, updating technological frames regarding what the product can do, how it is used, and how it is compared with other product technologies.

The second important locus of interaction in existing models of technological framing is that of consumers and producers interacting through traditional media. Traditional media, such as industry trade publications and popular press coverage of new products, provide further opportunities for collective sensemaking (Kaplan \& Tripsas, 2008; Rosa et al., 1999; Kennedy, 2008; Navis \& Glynn, 2010), where new frames are proffered and existing frames are shaped. Technological framing is generated in part through taking cues in stories (Rosa et al., 1999) from various media that "typically takes the forms of sales reports, inventory information, trade 
magazine reports of 'hot selling' items, newspaper articles, rumors or gossip with connections to past, present, and future courses of action” (Anand \& Peterson, 2000: 271).

Past accounts of the role of media in product market evolution has established how it can help to shape the technological frames in a product market, such as the legitimacy of different producers or the categorization of products that are released (Navis \& Glynn, 2010; Porac, Ventresca, \& Mishina, 2002; Rao, 1994). For example, as we have noted, traditional magazines and industry trade journals were instrumental in helping to shape a collective interpretation of how new products fit into the emergent "minivan" market, with implications for which producers' designs would be adopted in this new vehicle category (Rosa et al., 1999).

While the role of traditional media in product market evolution is well-established, a further locus for shaping technological frames has recently emerged. Increasingly, social media is a location for discussion about new and forthcoming products, such as the intense interaction outlined in our opening example of technology blogs covering the forthcoming Apple tablet product. By examining the role of social media in shaping technological frames, we address the need to update and extend our understanding of technological framing and to explicitly include the role of social media. In a recent review of the framing literature, the authors noted that "further research would also benefit from a processual focus on how technological frames are constructed and evolve" (Cornelissen \& Werner, 2014: 203), a point shared by other authors about the need for a "dynamic perspective of frame change as an ongoing interpretive process" (Davidson, 2006:30). We next theorize some of the key elements that underpin the shaping of technological frames in the context of social media.

\section{TECHNOLOGICAL FRAMES IN THE CONTEXT OF SOCIAL MEDIA}


Social media require us to revisit existing models of management and organization that were based on the characteristics of traditional media, given that "social media are technologies that enable the presentation, storage, and flow of information in ways that are difficult or impossible in other media." (Leonardi \& Vaast, 2017: 152). In this section we develop the specific characteristics of social media that are important to consider in the shaping of technological frames, after further describing in broad outlines how social media provides a platform for rumor communities.

Social media are defined as computer mediated platforms that allow communication that is visible to others and facilitates information sharing, user-created content, and collaboration (Leonardi \& Vaast, 2017; McFarland \& Ployhart, 2015). The affordances offered by social media mean that information can be exchanged in ways that compress time and space (Seong, 2017), allowing individuals to not only communicate across distances but also share experiences for which there is a permanent public record of the discourse over time. Social media have provided a new means of communication that is unprecedented in scale and speed (Leonardi \& Vaast, 2017; McFarland \& Ployhart, 2015). As we will outline in the following sections, and as is summarized in Table 1, an elaborated model of how technological frames are shaped in modern society needs to take into account the characteristics of social media working alongside traditional media.

\section{-- INSERT TABLE 1 ABOUT HERE --}

The distinct features of social media when compared with traditional media span issues of interaction, aggregation, and speed, as is outlined in Table 1. McFarland and Ployhardt (2015) 
provide a broad review of how social media is distinctive from traditional media with a focus on these three domains, which is also echoed in other recent theoretical treatments of social media (e.g. Seong, 2017). First, when compared with traditional media, online social media platforms afford a much higher degree of interaction between individuals - which is based on wider access, more anonymity and interdependence. Secondly, as also summarized in Table 1, social media provides a greater ability to aggregate past experience, as information is visible for long periods of time and the record is kept distributed across social media platforms. Finally, the speed at which collective sensemaking is updated as a product evolves is much higher on social media compared with traditional media (Seong, 2017).

\section{Online product rumor communities using social media}

Online product rumor communities are collectives of individuals exchanging propositions about forthcoming products and make use of social media platforms that barely existed during earlier eras of theorizing about technological frames and product market evolution. Indeed, earlier scholars of product market evolution could not have imagined the scale and scope of the exchange of propositions about forthcoming products that occurs online today. This also reflects how researchers have begun to view social media as shifting the media landscape from a single public sphere into multiple segmented "interaction arenas" (Bromberg \& Fine, 2002) where audiences are more active (e.g. Etter, Ravasi, \& Colleoni, 2018). Such arenas host interactions with multiple actors, including focal organizations (Aula \& Mantere, 2013) and other stakeholders such as investors, suppliers, and analysts. Because these arenas are partly overlapping, this enables networked narratives (Barros, 2014) and new forms of reputational dynamics and social valuations (Etter et al., 2018) that make online product rumor communities 
important spheres for discussion, debate, and influence when it comes to shaping technological frames.

The concept of an online product rumor community builds on recent work on rumor communities of political discourse that has highlighted the sensemaking that occurs in that context. Edy and Risley-Baird (2016:590), for example, have noted that rumor communities provide social contexts that shape rumor activity, and that rumor is not merely passed person-toperson in a chain but is a broader collective activity stating: "thinking of rumors as collective meaning making suggests the presence of rumor communities rather than the rumor chains suggested by traditional transmission."

This view is strengthened by other prior arguments that rumors do not always spread simply as information cascades (Buckner, 1965), but rather they are spread based on the credibility of the transmitter and the plausibility of the content relative to the social context. The credibility and plausibility reaches a threshold for the social group to transmit the rumor (Fine \& Khawaja, 2005), even if the rumor may not be credible or plausible to those outside the community. Instead of blindly spreading rumors, participants of a rumor community, upon hearing a rumor, ask themselves, "Are these claims that could reasonably be thought likely to happen within the world as we know it?" (Fine \& Khawaja, 2005:190). This parallels Weick's (1995) distinction between sensemaking and interpretation as one of invention and discovery, respectively. Sensemaking is a process of generation, "which emphasizes how images of a wider reality are created, maintained and rendered objective" (Powell \& Colyvas, 2008: 284). In summary, rumor communities act as a nexus for sensemaking about forthcoming products among distributed and diverse individuals. 
While we began with an example from Apple, a company whose anticipated product introductions are famous for generating rumors, there are a vast array of other product markets that feature this dynamic — including automobiles, consumer electronics, medical devices, recreational equipment, cultural products such as movies or video games, and many others. For example, an online product rumor community regarding innovations in photography recently consisted of individuals exchanging product rumors about a potential new class of "focus-free" camera, with individuals discussing this potential innovation across a number of blogs and forums.

Across various social media platforms, individuals may build on early rumors with their own further product propositions, adding new information as it becomes available. Taken together, individuals engaging in discussions across blogs, forums, and other social media define an online product rumor community devoted to a domain of shared interest. In summary, online product rumor communities afford new opportunities for debating and updating rumors and propositions, and we will demonstrate how this in turn shapes technological frames.

\section{Roles of producers, consumers, and traditional media}

With the advent of online product rumor communities, the role of producers, consumers, and traditional media shift, as we also outline in Table 1. Before social media, producers influenced technological frames by traditional marketing and public relations activity such as making keynote speeches, issuing press releases, and through their influence on editors in traditional media. For example, in one ethnographic study of a firm launching an early variant of RFID technology, the product launch was emphasized as "an activity planned and prepared by the corporation, [which] provided an announcement of relations between the internal 
constituency and members of a proposed external constituency" (Simakova \& Neyland, 2008:

100). This activity was heavily controlled by the firm's marketing department, as they

endeavored to create "compelling RFID stories" that were "relevant to specific audiences, users, corporations and so on" (Simakova \& Neyland, 2008: 108). With the advent of online product rumor communities, producers' deliberative framing actions now compete with the shaping of technological frames that happens through the rumor community.

In existing models of technological framing, consumers influence frames in part through sharing solutions to problems or proposing new ways to make use of a product — perhaps changing understandings of its use. One example can be seen in "turntablism," where the record turntable was repurposed from a machine for playing music to a new, secondary frame as a musical instrument (Faulkner \& Runde, 2009). With the advent of online product rumor communities, there is an additional way in which consumers may interact and shape frames, as we will develop further below.

Finally, the role of traditional media is likely to diminish in the context of online product rumor communities, as there will be social media to assist in the framing that previously was under the purview of well-controlled media channels. Indeed, traditional media now often have a social media arm to provide more immediate and dynamic aspects to their traditional methods of engagement. However, much of the activity of online product rumor communities is centered on platforms that are independent of traditional media, and so the effect will be to reduce the influence of traditional journalists and other gatekeepers in these institutions.

Above, and as we have outlined in Table 1, we have described the characteristics of social media that motivate the need for new models of how technological frames develop and how online product rumor communities provide a new important additional locus for this 
shaping activity. We now turn to the process by which online product rumor communities shape technological frames.

\section{A MODEL OF RUMOR COMMUNITIES AND TECHNOLOGICAL FRAMES}

In Figure 1 we provide an overview of a model of how activity in an online product rumor community influences the shaping of technological frames over the course of a rumor life cycle. This model is built on extant theory of technological frames and product market evolution that describe how technological frames are held by consumers, members of producer firms, and by other institutional actors, such as journalists in traditional media or government policy makers (e.g. Kaplan \& Tripsas, 2008; Grodal et al., 2015; Taylor, 2010). Individuals may hold disparate frames, or at times they may develop more collective and widely shared technological frames.

For example, the frames for what constitutes "nanotechnology" were at first not widely shared, but over time a more collective framing of this technology developed (Granqvist, Grodal, \& Woolley, 2012). Collective technological frames as well as individual frames serve to influence product market evolution by specifying expectations for individual products that are released using a given technology (Kaplan \& Tripsas, 2008). The frames we focus on are those that are being developed in the "pre-history" of a product (Kirsch et al., 2014), a period in which the product is not yet released, yet there is anticipation of a forthcoming new innovation. Recent work has drawn attention to the need to consider this nascent period of product markets (Kirsch et al., 2014; Grodal et al., 2015; Suarez et al., 2015), as without such understanding we neglect important path-dependent processes that underlie the full scope of product market evolution.

-- INSERT FIGURE 1 ABOUT HERE -- 
In the next sections we describe in detail how activity in an online product rumor community can influence technological frames. As outlined in the upper shaded portion of Figure 1, we break rumor community activity down into three phases that define the life cycle of an individual product rumor discussed within the community. Work in the sociology of rumor describes rumor as "the quintessential collective sense-making activity" (DiFonzo, Bourgeois, Suls, Homan, Stupak, Brooks, Ross, \& Bordia, 2013: 379), and rumor progression encompasses three main phases (Bordia \& DiFonzo, 2004). In the first phase, a nascent rumor is introduced to participants in an interested community. In the second phase, there is a deliberation of possible futures by the community — a phase we will define as "conceptual prototyping." Finally, there is a phase of convergence and stabilization of rumor and proposition. The boundaries between these phases can be somewhat fluid, so we represent them as overlapping arrows. This process follows a model of cultural evolution (Campbell, 1969), where there is an initial divergence of inquiry, followed by convergence through collective sensemaking.

With each cycle of debating and discussing rumors about a forthcoming product, there are opportunities to influence and shape the associated technological frame. Through repeated cycles of the life cycle of a product rumor within the community, the frame undergoes repeated adjustments. As is diagrammed in the very top of Figure 1, and as will be developed next, the social media characteristics we have already outlined serve to propel the activity in the rumor community across the three phases, starting with the development of nascent rumor.

\section{Development of nascent rumor}


To begin to understand how a rumor community can shape technological frames, we have to first outline some of the ideas from the sociology of rumor and, in particular, why rumors arise and how they begin.

The sociology of rumor. Studies in the sociology of rumor have established that rumors are likely to appear in circumstances of ambiguity and shared interest. One classic definition of a rumor is that it is a proposition, passed person-to-person, with "a lack of secure standards of evidence" (Allport \& Postman, 1947: 220). Allport \& Postman's insights were formulated into the stylized 'basic law of rumor' $(r=i * a)$, where the level rumor spread (r), depends on the level of interest (i) multiplied by the level of ambiguity (a). Extending this to more sociological concepts, Shibutani (1966: 165) labeled rumor as "improvised news" and argued that: "Rumor is a collective transaction whose component parts consist of cognitive and communicative activities; it develops as men [sic] caught together in an ambiguous situation attempt to construct a meaningful interpretation of it by pooling their intellectual resources". In our context, a product rumor is a proposition about the attributes of a forthcoming product, with uncertain evidence of its veracity. Such rumors arise under conditions of ambiguity and shared interest about forthcoming products. Rumor can be seen as an interpretive act, where "rumor reflects the future as filtered through the recent past" (Fine, 2007:6).

The effect of wide access and anonymity. Wide access and anonymity makes social media platforms ripe for producing and disseminating product rumors. Participants in an online product rumor community include those actors highlighted in prior work on sensemaking in product markets (Kaplan \& Tripsas, 2008; Rosa et al., 1999), such as consumers, producers, industry analysts, and journalists. Any of these actors can serve as core participants, actively 
contributing to discussion, or more peripheral participants, rarely if ever posting material and merely reading the discussion.

A new actor also appears with the advent of social media: the "tech bloggers." Tech bloggers are individuals who "create and disseminate news, opinions, reviews, advice, and other information about technology developments" using social media platforms (Vaast, Davidson, \& Mattson, 2013: 1070). Furthermore, “[i]n contrast with journalists' practices of fact checking and protecting sources, bloggers are more likely to distribute rumors and opinions, to let the 'truth' emerge through conversations with each other and with readers and to link to their sources (typically other bloggers)" (Vaast et al., 2013: 1072). Research has shown that tech bloggers have carved out a role and an identity distinct from traditional journalists in their discursive practices, focusing on discussing current and forthcoming innovations in a highly iterative and social manner (Vaast et al., 2013).

With wide access and anonymity, an online product rumor community is characterized by fluid boundaries of membership (Seidel \& Stewart, 2011). Wide access lowers barriers for participation and information consumption (Faraj et al., 2011), and individuals can access these social media platform technologies from work, home, or on the go using mobile devices (Treem, Dailey, Pierce, \& Leonardi, 2015). In the online product rumor community, participants typically employ usernames or avatar identities, providing the perception of anonymity in contrast to faceto-face interactions, and increasing the likelihood of rumor activity (McFarland \& Ployhart, 2015).

Who starts nascent rumors? Many of the social media platforms that form a product rumor community are structured as blogs (Droge, Stanko, \& Pollitte, 2010), with a front page resembling a rolling newsreel with commenting mechanisms and an associated forum for further 
discussion and commentary. Participants scan diverse sources for new information and, as they become aware of rumors, they promote these rumors on these platforms. This practice establishes attention from further core participants, such as consumers and analysts, who themselves are dealing with the ambiguity inherent in the evolution of the product market and who may offer rumors to the community themselves. Tech bloggers and other core participants active in the community at this stage may present several rumors, not all of which may be taken up with the same level of interest. Core participants will have built reputations around involvement in this process over the course of several product rumor life cycles. This reputation grants core participants, especially certain tech bloggers, a legitimacy in framing product rumors as "improvised news" (Shibutani, 1966).

There is a natural audience for rumor, such as potential consumers who share a common interest in the evolving understandings and "market cues" (Porac, Thomas, \& Baden-Fuller, 1989) that signal possible product attributes and price-points. A high level of interest can be due to many factors: for example, consumers may have interest in learning about products within a new market category based on the high relative cost of a purchase, such as seen in behaviors of consumers in the automotive sector (Rosa et al., 1999). They may also have interest due to the identification they have with a certain brand (Muniz \& O’Guinn, 2001). Analysts may have interest in an area due to the need to conduct primary empirical research and produce guidance notes for investing clients, or stake their professional claim on a domain (Hsu \& Hannan, 2005; Zuckerman, 1999). In the relative absence of information from legitimate sources, the online product rumor community serves as an "informational black market" (Kapferer, 1990: 9) where individuals can gain insight about product market evolution. 
Seeding propositions that influence initial frames. Rumor, as a constructive form of provisional meaning, can provide a platform upon which further propositions are based. For example, an initial rumor may deal with what producers might enter a market. Further propositions might be offered on what features their innovations may include if they do. While rumors include propositions without secure "standards of evidence" (Allport \& Postman, 1947) in terms of who has transmitted them, other propositions may have known sources, further providing a thread of texts that together establish discourses on a possible new innovation. A rumor can serve as the starting point upon which a series of further posts is created at a later point in time. Rumor will not simply propagate as a social contagion, but instead may start and stop at different points in time, in a process called 'rumor recursion' (Kawachi, Seki, Yoshida, Otake, Warashina, \& Ueda, 2008). Under certain circumstances, rumor is a generative form of social cognition (Bordia \& DiFonzo, 2004), where rather than being evaluated because of the credential of the initial speaker, it is judged on its plausibility by audiences (Fine, 2007). As a rumor evolves, it can serve as a form of sensemaking independent of the ultimate veracity of the initial proposition.

As individuals consider rumors and associated propositions, they draw from initial technological frames that influence their understanding of the situation. In turn, initial rumors and propositions can influence which initial frames are drawn upon to make sense of the situation. Past work on technological frames has described how new events—-such as a new technology or other shocks - can both activate existing frames as well as begin a process of exploring for new frames (Davidson, 2006), and the awareness of a new rumor can trigger this process within a rumor community. As we indicate in Figure 1, the development of nascent rumors seeds propositions to the frames of producers, consumers, and others. Akin to the role of 
information that is purposely "leaked" by producers to the market (Hannah, McCarthy, \& Kietzmann, 2015), propositions seeded from rumor communities can result in the initiation of certain technological frames that will start to shape the initial understandings on which the evolution of the product market depends.

\section{Conceptual prototyping}

In the rumor community, increased discussion and debate around different rumors and propositions will lead to "conceptual prototyping." Conceptual prototyping involves community participants testing out propositions using the immediacy afforded by social media for experimentation, as well as the interdependence among individuals as they build upon each others' propositions. Studies in the sociology of rumor describes "effortful processing" (Bordia \& DiFonzo, 2004) of a rumor and related propositions among participants as a rumor unfolds, which is the dynamic we capture here. In this section, after considering how two particular aspects of social media propels activity in the rumor community, we discuss how the participants broaden from core participants to include more peripheral participants in the community and how this phase is marked by collective sensemaking increasing the range of options for reframing.

The effect of immediacy and interdependence. While all of the distinctive characteristics of social media are important, immediacy and interdependence play a central role at this stage of rumor progression. Rumor communities use of social media means they are able to provide immediate updating on much faster cycles than with traditional media (McFarland \& Ployhart, 2015), propelling the use of social media as an arena for debate and discussion. The effect of this 
is that the rumor community is more effective for real-time collective sensemaking among diverse and distributed individuals.

Using social media, participants are able to build on each others' propositions about a future state of affairs, highlighting how social media enables interdependence (McFarland \& Ployhart, 2015). Some participants may participate due to the opportunity to further establish their reputation in dealing with rumor, as seen in other forms of community organization (O'Mahony \& Ferraro, 2007). With other, less engaged participants, identification with the community may be less and, as Shibutani notes, "where ego-involvement is low, rumors may be passed on for amusement" (1966: 165). These participants may be driven in part to participate by the intrinsic enjoyment of participating in a community that builds and extends propositions about forthcoming products.

Prior research on open source software (von Krogh, Haefliger, Spaeth, \& Wallin, 2012), vehicle design (Seidel \& Langner, 2015), and consumer products (Baldwin, Hienerth, \& von Hippel, 2006) have demonstrated how interdependent community members are willing to engage for the enjoyment of collaborating on product innovations. The same dynamic can be expected in relation to exchanging rumor and propositions on forthcoming products, and the ease by which social media provides both immediacy and interdependence helps to propel rumor community activity at this stage, drawing in more perspectives.

Collective sensemaking influencing frame expansion. Conceptual prototyping is, as we are defining it, different from the physical prototyping that characterizes much of the behind-thescenes work within producer organizations (e.g. Hargadon \& Sutton, 1997) and from the user prototyping that occurs in other online settings (e.g. Jeppesen \& Frederiksen, 2006). Conceptual prototyping, as we conceive it, is concerned with a collective testing out of propositions about 
forthcoming products within a realm of discourse, not testing actual products, and this implies two things: that the collective sensemaking process may lead to new propositions for a product, and that discourse within an online product rumor community is subject to similar processes of divergence and later convergence as is seen in physical prototyping.

Practices common in physical prototyping will be expected within conceptual prototyping as well. For example, one would expect the extensive use of analogy in evaluating additional propositions for a forthcoming product. The use of analogical processes in innovation is well established. For example, product designers at IDEO were found to use many analogies that drew from their experience across industries in the development of new physical prototypes (Hargadon \& Sutton, 1997). More generally, generating prospective solutions to problems often entails reaching out to other domains and then "stretching, bending, and positioning" these analogous solutions (Glaser, Fiss, \& Kennedy, 2016). For example, a community participant in a smart phone rumor community who has experience with a curved TV may start a rumor that there a curved smartphone might be introduced by making an analogical extension to curves in TV technology. A new proposition for the forthcoming product might then be added, using the base rumor as a starting point. Studies of the digital photography industry showed how individuals used analogies grounded in technological frames in their current industries as they considered their entry into the market (Benner \& Tripsas, 2012). Analogical reasoning has been found to be a powerful dynamic in framing generally (Gavetti, Levinthal, \& Rivkin, 2005), and the use of analogy within conceptual prototyping in the rumor community can therefore also work to shape associated technological frames.

A second practice expected at this phase is rewarding novelty. After an initial product rumor, individuals may be rewarded for providing novel extensions to the propositions, as 
individuals generally receive intrinsic rewards for building on the ideas of others (McLure Wasko \& Faraj, 2000; von Krogh et al., 2012). In our example, individuals might build on the curved smartphone case to propose that it would lend itself to a palmprint identity reader at the back, since it would follow the curve of the hand holding it. The cumulative effect of the first two practices is a widening of the propositions circulating within the community that could extend far beyond the initial rumor.

How does this widening of propositions influence technological frames? With a greater number of propositions, individuals will also be working across an expanding number of frames by which to make sense of the possibilities afforded by widening propositions. For example, in the development of one of the first eBook readers, there was a question of whether the primary technological frame was to be "computer-like" or "book-like" (Seidel \& O’Mahony, 2014). A "computer-like" frame would imply that one would scroll through text, such as on a computer, whereas a "book-like" frame would imply you page through text, one page at a time. While in the case of the eBook, these competing frames were worked out differently among developers in each organization. With the advent of online product rumor communities, propositions about different ways to get through text—such as scrolling, page turning, or other means—would expand the repertoire of frames considered for the emerging eBook product market. The online product rumor community as an arena for conceptual prototyping serves as a space whereby individuals may discuss and debate propositions about the future, enabling them to update associated technological frames at the same time.

Frame expansion is a process that has been seen in other contexts, but usually this is seen as a directed process by which managers seek to try out differing frames for some directed propose. For example, in a parallel process of "framing contests" (Kaplan 2008), individuals 
within organizations advance different narratives about future development drawing on different frames. Often different frames compete within an organization (e.g. Barrett, Heracleous, \& Walsham, 2013; Leonardi, 2011; Mazmanian, 2013; Treem et al., 2015), but we draw attention to the frames that can compete within a community that is engaging in purposeful sensemaking regarding what frames are appropriate to a future course of action.

During this stage, there still may be no stable direction within the rumor community and still a wide variety of frames in play, with different and incongruent frames used by different actors. In addition, different actors will be more receptive to updating their frames depending on their situation. For example, producers vary in their perceived competitive position: An incumbent that has considerable market power may be blind to the challenges of ongoing product market evolution and may be drawing on outdated frames (Tripsas \& Gavetti, 2000). Individuals within such organizations are unlikely to seek out arenas to test their ideas and conceptions of forthcoming products. In contrast, other producers may perceive a high degree of rivalry, either from drawing upon their own prior experience or from clear levels of competitive threat (Benner \& Tripsas, 2012) and therefore be more open to updating associated technological frames.

\section{Proposition stabilization in the context of interdependence and permanence}

Past studies of the sociology of rumor have demonstrated how following expansion of rumor, there is a convergent dynamic whereby rumors and propositions stabilize into a dominant proposition (Bordia \& DiFonzo, 2004; Shibutani, 1966; DiFonzo et al., 2013). As we will describe in this section, during this phase participants seek coherence across propositions. This, in turn, will be reflected in the cognitive embedding of the dominant propositions (Porac \& Rosa, 1996), with the dominant propositions featured on the main pages of online community blogs. 
This practice has sometimes been termed a form of "innovation journalism" (Carroll, 2009; term coined by Nordfors, 2001) or "technology innovation discourse" (Vaast et al., 2013) where dominant propositions about forthcoming events are widely shared, and we will describe how this in turn provides sensegiving opportunities to different stakeholder groups (e.g. Gioia \& Chittipeddi, 1991), which in turn can shape the development of a collective technological frame.

The effect of interdependence and permanence. The interdependence and permanence of social media propel activity in this phase (McFarland \& Ployhart, 2015), and continued interdependence means that individuals have the ability to resolve among themselves varied interpretations of rumors and propositions, as they work toward a likely dominant proposition.

As with other online communities, such as in open source software development, a core group of participants work across the contributions of different individuals and have the reputation to advance certain propositions more strongly (O’Mahony \& Ferraro, 2007). In rumor transmission generally, Shibutani (1966: 165) reflected on how core members seek coherence among different viewpoints: "whenever ego-involvement is high, ... critical ability is likely to be enhanced. Reports are examined for adequacy of sources and for plausibility, and chances for personal intervention with private views that are cathartic are held to a minimum." Core members of the community—such as tech bloggers and repeated contributors—would be expected to engage in interdependent practices to stabilize rumors and propositions into a dominant proposition.

Emergent research on "creative synthesis" advances that innovative concepts are continually tested for coherence with each other, as a form of synthesis (Harvey, 2014). We know from prior research that development teams working together look for coherence not only 
among the attributes of the physical products they are developing but also in their associated concepts (Seidel \& O'Mahony, 2014). Extending this to the domain of rumors and propositions about forthcoming products, this final phase of the rumor process is expected to focus on establishing coherence. In our smartphone example, community participants may at this stage test for coherence among rumors of a curved smartphone design and propositions of added features that would consume battery life, debating plausible combinations that fit past experience in smartphone design concepts.

The permanent record of past discussion across social media helps in the effort to establish stabilization. All past views are searchable on social media, and so those who are most central are able to aggregate insights from across the community to propose a synthesis regarding the forthcoming product innovation. Certain core participants - tech bloggers and others who have established reputations among peers - are likely to serve as key arbiters of the dominant proposition that in turn will influence collective frames for thinking about the evolving product market. As core participants gather and synthesize propositions through coherence testing, they are compiling material for inclusion for future dissemination of the dominant proposition. Another way to conceptualize this activity by core participants is through innovation journalism which is concerned with, "reporting about the people, processes, practices and politics associated with innovation, be they related to computer technology trends, health and medicine" (Carroll, 2009). The practitioners of innovation journalism on social media are tech bloggers, who have established a distinctive domain of reporting out the direction of forthcoming products (Davidson \& Vaast, 2009; Vaast et al., 2013), and these individuals as well as other core players are able to engage in sensegiving, serving to help to shape a collective technological frame. 
Sensegiving influences the collective technological frame. As a proposition stabilizes, it has the potential to influence diverse technological frames into a collective frame through sensegiving by key actors. One practice that facilitates this is what is known in some online communities as a "rumor roundup," as illustrated at the beginning of this article, where tech bloggers provide an overview of state of the "uncertain knowledge" (Fine \& DiFonzo, 2011) circulating in the online product rumor community. In the rumor roundup, core participants summarize what has been considered in evaluating rumors and what they are advancing as the dominant proposition. In our smartphone example, a summary of different curved smartphone rumors might be reviewed by a tech blogger, who then summarizes what they consider the most likely: a curved smartphone of a certain dimension with certain attributes - such as two cameras but no palmprint identification device. Among different core participants—such as different tech bloggers and highly engaged consumers - there may be some disagreement about some attributes, but overall a dominant proposition is likely to take form.

A dominant proposition will then help to influence a collective technological frame. As seen in other contexts, a collective frame is not guaranteed during times of ambiguity (Leonardi, 2011) but takes effort to resolve incongruence across frames. For example, in one government program, different actors negotiated frames into a separate "truce frame" that didn't reflect any of their individual initial technological frames (Azad \& Faraj, 2008). This truce frame was only developed after a process that included what was termed frame differentiation, frame adaptation, and frame stabilization. In the context of online product rumor communities, conceptual prototyping phase helps to expose an expansion of frames and, though extending rumors with additional propositions, the associated frames can also be adapted. In this final stage of proposition stabilization, frames themselves can be stabilized into a collective frame that may 
take on elements that blend prior frames. Once propositions have stabilized into a dominant proposition, sensegiving activities as described above make it more likely that a collective technological frame is formed.

\section{Repeated evaluation and learning within the rumor community}

Above (and as illustrated in Figure 1) we focused on rumor community activity through one rumor life cycle, from the development of a nascent rumor though to proposition stabilization in the pre-history of a product. An expanded view situates the life cycle we described to include the period after a product is released, and recognizes that this will be repeated over multiple rumor cycles. For example, members of a rumor community dedicated to digital photography would be expected to follow a series of rumors about a stream of anticipated products, track actual products as they are released to the market, and then learn how close the community expectations have been to what is produced. In this section, we address repeated evaluation and learning within a rumor community.

The extended and repeated process of rumor community activity and technological framing, which includes both the pre-history phase followed by a product release phase, is illustrated in Figure 2. While prior models of technological framing have focused on the activities centered on when products are released to market (e.g. Kaplan \& Tripsas, 2008, Rosa et al., 1999), we have extended the process backward to consider the entire process to include the

pre-history of products. We will describe the entire timeline next, and we will also outline the implications of repeated evaluation and learning for expanding our understanding of technological frames and product market evolution. 


\section{-- INSERT FIGURE 2 ABOUT HERE -}

As illustrated in Figure 2, with labeled arrows starting with (a), in the pre-history of a specific product, a rumor cycle generates a proposition about the forthcoming product, as developed previously, and the community also shapes the pre-history technological frame (b). Figure 2 includes the realm of product market activity, and this figure includes the implication that a pre-history technological frame can influence producers (c) as they attend to flows of information from communities (Fisher, 2018) while developing the forthcoming product.

Once a product is developed and released to the market, the pre-history technological frame (d) affects initial consumer understanding and adoption of the product, as existing frames provide a means for understanding new technologies (Kaplan \& Tripsas, 2008). As consumers, producers, individuals within media, and others gain experience with the actual product, they further update their associated technological frames (e) (Rosa et al., 1999). The rumor community evaluates the actual product in light of its associated updated frame (f) and compares this with the prior product proposition. As a dominant product proposition is compared with an actual product that is released, there is the opportunity for the community to learn to adjust their expectations for future rumors life cycles (cf. Riedl \& Seidel, 2018).

Several implications follow from this expanded and repeated view of rumor community activity. First, producers may be influenced by rumor communities opening up or closing down the options they consider while developing their product innovations. Since producers are able to follow discussions within the rumor community (Hannigan, Seidel, \& Yakis-Douglas, 2018), the associated conceptual prototyping and the expansion of pre-history frames that develop, this may open up possibilities for consideration during the development of the product. Likewise, during 
proposition stabilization, propositions and frames both converge within the community, with possible corresponding influence on producers. Pre-history frames may help to influence the specific product innovations that get produced as part of product market evolution.

A second implication of considering the full timeline is that rumor communities can learn from repeated evaluation, which implies that communities can update their ability to assess product market evolution. As previously seen in the Apple example, a reflection on lessons learned is often seen within an online product rumor community as a "rumor roundup" where rumors are evaluated and eventually compared with final products that are released. Learning is a central factor for motivation and engagement within many online communities, such as in software development (Lakhani \& Wolf, 2005) or design (Riedl \& Seidel, 2018). Similarly, as individuals experience successive iterations of the rumor life cycle, they will have the opportunity to observe patterns of how rumors develop and unfold in a rumor community.

Online communities circulate both explicit and tacit knowledge (Faraj, von Krogh, Monteiro, \& Lakhani, 2017), and explicit knowledge in an online product rumor community might be centered around who has provided reliable sources of rumor in the past. Tacit knowledge in online communities can be seen in the unfolding understanding that takes place in the process of online conversations, where "repeated interactions, [offer] the possibility to ask contextualizing questions, the validation of answers, the mutual challenging of partial answers, the presentation of an idea, and its further refinement through dialogue [that] gradually shape participants' comprehension of what is going on" (Faraj et al., 2017: 676). Through repeated dialogue in the community and repeated observation of how dominant propositions compared to subsequently-released products, individuals learn to adjust expectations for future life cycles of product rumors and how rumors and frames influence each other over time. 
Learning to adjust expectations with regard to product rumors will be especially pronounced with core participants in the community, such as tech bloggers, due to their close attention to both explicit and tacit knowledge flows (Dahlander \& Frederiksen, 2012). Therefore, such core participants, in particular, will get better at making propositions, at understanding who provides valuable information, and at synthesizing myriad sources of information over the life cycle of a product rumor. An effect of repeated evaluation and learning in the rumor community is that the community itself may develop technological frames and related expectations for forthcoming products that are not in-line with producers' interests, forming a stakeholder group (Fisher, 2018) distinct from firms themselves. Contemporary examples of this phenomenon might include rumor communities associated with electric vehicles debating and ultimately narrowing the range of frames of what types of cars are considered socially-minded electric transportation. In summary, the presence of online product rumor communities provides not only an ongoing means by which individuals discuss emergent product innovations but also means by which a community develops its own perspective on the frames by which products may be evaluated.

\section{DISCUSSION}

We have investigated the role of online product rumor communities in shaping technological frames that then influence product market evolution. Our model describes how nascent product rumors form, are discussed and debated, and then stabilize over time, with different influences on technological frames in each phase. The process we describe takes place on social media platforms before products are introduced - the pre-history of the product that 
will eventually be brought to market—providing a location for collective sensemaking and the shaping of technological frames that has received little research attention to date.

We believe our model makes three major contributions. First, we expand the timeline of understanding of the role of collective sensemaking in product markets by exploring how online product rumor communities use social media to generate propositions about forthcoming products and the effect on technological frames. There has been an increasing interest in how collectives work to make sense of ambiguous situations, and emerging research on "interstitial spaces" (Mische, 2009; Furnari, 2014) or "free spaces" (Rao \& Dutta, 2012) looks at how "actors temporarily suspend some aspects of their identities and involvements in order to generate the possibility of provisionally equalized and synchronized relationships." (Mische, 2009: 21). Social media platforms that host online product rumor communities provide a "free space" for individuals to purposely construct meaning around forthcoming innovations and meet their needs for synchronizing their understandings across time and space (Seong, 2017), and by expanding the timeline of this interaction to include the pre-history of products, we demonstrate the importance of these early moments in frame expansion and frame stabilization even before products are released to market.

Our second contribution is to show how product rumors can serve not only as collective sensemaking, but also a generative sensegiving role (Gioia \& Chittipeddi, 1991) as a platform upon which further propositions are based that may, in turn, shape technological frames and associated understandings. With our focus on conceptual prototyping in a rumor community, this generative view stands in contrast to commonly held views on rumor, where the term has a pejorative connotation referring to 'something wrong or misleading' (Fine \& DiFonzo, 2011:18). In an organizational context, rumor is often depicted as harmful with accompanying normative 
guidance on how to extinguish it (Kimmel, 2004; Houmanfar \& Johnson, 2004; DiFonzo \& Bordia, 2000). In contrast to this pejorative view of rumor, we view product rumor as a means of both collective sensemaking and sensegiving as individuals seek to understand and determine the trajectory of future innovations, shaping associated frames and in turn opening up or closing down options considered by individuals.

Our third contribution is to propose how producer firms and online communities are increasingly intertwined, even if the firms are not actively partnering with online communities as recognized stakeholders (Fisher, 2018). In contrast to rumor communities, there are also "user communities" that are focused on actively making innovations that benefit firms, ranging in examples from computer-generated musical instruments (Jeppesen \& Frederiksen, 2006) to cars and t-shirts (Langner \& Seidel, 2015). In user communities participants may not only collectively create artifacts but also collectively work out how to ascribe meaning to their innovation, and user innovators can "play a decisive role in the initial creation of innovative products as well as their subsequent take-up and diffusion" (Faulkner \& Runde, 2009: 442). Moving from a focus on online user communities to online product rumor communities, one implication of our model is that the collective sensemaking of forthcoming products and the associated framing may help users to more quickly "take-up" and adopt innovations once they are available, compared to situations where there is no community. Members of online product rumor communities have had the opportunity to shape the frames that will define how forthcoming products are evaluated and may develop a distinct perspective on the frames by which products may be evaluated. As we will describe, the precise dynamics of this adoption process is an important area of potential further empirical investigation. 


\section{Future research on the dynamics of rumor communities}

In drawing on the sociology of rumor and connecting this work to studies of social media, we contribute to a stream of work that is recognizing how social media affects classic concepts in management and organizational theory, with recent examples exploring the impact on organizational reputation (Etter et al., 2018) and technology diffusion (Leonardi \& Vaast, 2017). Recent research on social media has acknowledged in passing how it provides a platform for the transmission of rumor, but such work has not yet connected fully to the rich literature in the sociology of rumor. Thus, while research looking at the effects of social media has begun to uncover phenomena such as "echo chambers" (Leonardi, Huysman, \& Steinfeld, 2013) and the spread of false claims through technology-mediated information cascades (Veil, Sellnow, \& Petrun, 2011), such work to-date has not yet examined the detailed dynamics of online rumor communities and how their structure and membership may influence rumor's role in shaping the interpretation and framing of ambiguous situations.

A first area of further research could be how the structure of social media platforms affect rumor transmission. As we discussed, early work in the sociology of rumor characterized rumor transmission as being diffused somewhat uncritically (Allport \& Postman, 1947), and this has been challenged by the constructionist model of improvised news as people "are not robots who parrot automatically what they have heard" (Shibutani, 1966:14). Although rumors may cascade among similar actors according to resonant views and beliefs (Fine \& Turner, 2001), it is an empirical question what types of social media platforms best enable rumoring and sensemaking and in what ways. While rumor is ontologically uncertain (Fine \& DiFonzo, 2011), it is not necessarily false, and while much current effort is made to explain the transmission of demonstrably false news (e.g. Vosoughi, Roy, \& Aral, 2018; Sunstein, 2009), going forward 
there can be further effort to understand the generative collective sensemaking afforded in social media.

A second area of study could focus on the rumors themselves. For example, empirical research could investigate when product rumors (and their associated communities) are most likely to happen — testing the generalized "law of rumor," probing the threshold where rumors begin, and exploring the degree to which these and other factors drive the generation and transmission of product rumors. Lab experiments or even simulation studies might be employed to model the details of rumor emergence in the context of technological framings and product market evolution.

A third area of study could be how different individuals contribute to differing degrees to the rumor community. There is already a well-established literature in organizational studies on online communities that traces the role of different individuals, such as how they gain status (e.g., O’Mahony \& Ferraro, 2007) or transition between core and peripheral roles (Dahlander \& Fredericksen, 2012). Large scale empirical tests using data scraped from online product rumor community blogs and forums could investigate how individuals take on different roles over time, and how different individuals draw upon frames in advancing their point of view in the community, while also shaping frames in turn.

A fourth area of study would be to investigate the evolution of online product rumor communities themselves. One particular area of interest would be how such communities choose the focus of their efforts, specifically whether they focus primarily on a product line, a brand, or an entire industry. Currently some rumor communities are focused primarily on a specific brand, similar to brand communities more generally (e.g. Muniz \& O'Guinn, 2001), where others are concerned with industry-wide issues. Longitudinal studies of industries could examine whether 
there are patterns by which online rumor communities change their focus over time, perhaps mirroring an industry life cycle.

\section{Future research on the shaping of technological frames}

We have described how there has been a long-standing interest in the role of frames as a means of cuing sensemaking and structuring social contexts, particularly in situations marked by high degrees of ambiguity (Powell \& Colyvas, 2008). A key contemporary concern in this domain is in explaining a more dynamic and processual view of how frames are shaped over time (Cornelissen \& Werner, 2014; Davidson, 2006). Although individuals often struggle to retain old frames (Benner \& Tripsas, 2012), new technological frames do develop, and we propose that the sociology of rumor connected with theories of social media provide a new lens through which to explore frame development and expansion.

Our study also points to opportunities to more deeply investigate the role of rumors and technological frames in the context of a new market category. Heeding the call from Kennedy \& Fiss (2013: 1141) that "instead of starting with stable category structures" category research should instead study "substructures as an outcome and accomplishment to be explained," our study points to a new arena by which category creation and associated technological frames may take place.

As future products are debated in online product rumor communities, the categories to which they fit are drawn upon by activating various technological frames. Past research in market categories has stressed the importance of studying meaning-making in the emergence of categories, but they often draw upon meso-level mechanisms of legitimacy as a main focus (Aldrich \& Fiol, 1994; Navis \& Glynn, 2010). Our model instead describes an important domain 
that can alter the course of new category emergence, both in terms of the ability to stabilize propositions about products within the market category and in shaping the technological frames that help to structure categories themselves.

Past research has pointed to two main classes of frames that are seen in problem-solving contexts, diagnostic frames that serve to address problems and prognostic frames that address potential solutions (Benford \& Snow, 2000). In some studies, such as in strategy-making, researchers have observed patterns in moving from diagnostic to prognostic frames (e.g. Kaplan, 2008) Other studies, grounded in new technologies, have found more of a mix of frames at any one time (e.g. Leonardi, 2011). Rumor and proposition within an online rumor community works to address both sensemaking of events as they are happening (a diagnostic focus) as well as to make claims about possible futures (a prospective focus). With our focus on the generative aspects of online rumor communities, especially with regard to conceptual prototyping, we would expect a mix of diagnostic and prognostic frames to be in play at any one time, but this is an area that would be ripe for future research.

\section{Future research on the interplay between rumor communities and firms}

Our study also has implications for future research on the dynamics between firms and online product rumor communities. Some of this research should be grounded theory building, using multiple real-world examples of online product rumor communities and tracing the effects of rumor in detail over time and across multiple organizations, expanding from past single casestudies of firms in the context of product rumors (Hannigan et al., 2018). In addition, in practice multiple firms are contesting a market, all of whom have access to the same online product rumor communities. Grounded theory building could investigate questions regarding the 
strategic use of insight from online product rumor communities as a source of competitive advantage, and perhaps how some firms focus on firm-specific communities (e.g.

Canonrumors.com), while other smaller firms may bridge industry-wide communities (e.g. Photorumors.com).

We have presented our model, as shown in Figure 1 and as expanded in Figure 2, as a complete cycle of the product rumor process, in common with other process models of technological evolution (e.g., Tushman \& Rosenkopf, 1992). However, the life cycle of a product rumor may be interrupted by news of the introduction of the product at any time, even before a dominant proposition is formed. In such a case, the effect of such interruptions by a producer (or by others within the industry) could be investigated in terms of how this effects the shaping of technological frames and overall product market evolution. In addition, it would be interesting to explore how rumor communities learn from product announcements in addition to product releases in terms of their willingness to agree on a shared product propositions and the convergence of associated technological frames.

\section{CONCLUSION}

With the introduction and widerspread use of social media, product rumors can now be shared on a scale and with a speed that was unthinkable to early scholars of rumor or to those who study product market evolution. Online product rumor communities provide an important but previously understudied component of collective sensemaking that has implications for how technological frames are shaped and the evolution of product markets. While perhaps easy to dismiss as mere hype, online product rumors provide the kernels of meaning-making that shape propositions about forthcoming products and the framing of interpretation and expectations. In 
forming arenas for collective sensemaking, and as a means for conceptual prototyping, online product rumor communities deserve continued exploration as one important component by which meaning is embedded in the framing, emergence, and evolution of product markets. 


\section{REFERENCES}

Abernathy, W. J., \& Clark, K. B. 1985. Innovation: Mapping the winds of creative destruction. Research Policy, 14(1): 3-22.

Aldrich, H. E., \& Fiol, C. M. 1994. Fools Rush in? The Institutional Context of Industry Creation. Academy of Management Review, 19(4): 645-670.

Allport, G. W., \& Postman, L. 1947. The Psychology of Rumor. New York: Holt, Rinehart, and Winston.

Anand, N., \& Peterson, R. A. 2000. When Market Information Constitutes Fields: Sensemaking of Markets in the Commercial Music Industry. Organization Science, 11(3): 270-284.

Aula, P., \& Mantere, S. 2013. Making and breaking sense: an inquiry into the reputation change. Journal of Organizational Change Management, 26(2): 340-352.

Azad, B., \& Faraj, S. 2008. Making e-Government systems workable: Exploring the evolution of frames. The Journal of Strategic Information Systems, 17(2): 75-98.

Baldwin, C., Hienerth, C., \& Hippel, von, E. 2006. How user innovations become commercial products: A theoretical investigation and case study. Research Policy, 35(9): 1291-1313.

Barrett, M., Heracleous, L., \& Walsham, G. 2013. A Rhetorical Approach to IT Diffusion: Reconceptualizing the Ideology-Framing Relationship in Computerization Movements. MIS Quarterly, 37(1): 201-220.

Barros, M. (2014). Tools of Legitimacy: The Case of the Petrobras Corporate Blog. Organization Studies, 35: 1211-1230.

Benford, R. D., \& Snow, D. A. 2000. Framing Processes and Social Movements: An Overview and Assessment. Annual Review of Sociology, 26: 611-639.

Benner, M. J., \& Tripsas, M. 2012. The influence of prior industry affiliation on framing in nascent industries: the evolution of digital cameras. Strategic Management Journal, 33(3): 277-302.

Bilton, N. 2009, December 28. What Would a 10-Inch Apple "iSlate" Look Like? New York Times. http://bits.blogs.nytimes.com/2009/12/28/what-would-a-10-inch-islate-look-like/.

Bordia, P., \& DiFonzo, N. 2004. Problem Solving in Social Interactions on the Internet: Rumor as Social Cognition. Social Psychology Quarterly, 67(1): 33-49.

Bromberg, M., \& Fine, G. A. 2002. Resurrecting the Red: Pete Seeger and the Purification of Difficult Reputations. Social Forces, 80(4): 1135-1155.

Buckner, H. T. 1965. A Theory of Rumor Transmission. Public Opinion Quarterly, 29(1): 5470.

Campbell, D. T. 1969. Variation and selective retention in socio-cultural evolution. Social change in developing areas $A$ reinterpretation of evolutionary theory, 19: 26-27. 
Carroll, C. E. 2009. Innovation Journalism. In C. Sterling (Ed.), Encyclopedia of Journalism. Thousand Oaks, CA.

Clark, K. B. 1985. The interaction of design hierarchies and market concepts in technological evolution. Research Policy, 14(5): 235-251.

Cornelissen, J. P., \& Werner, M. D. 2014. Putting Framing in Perspective: A Review of Framing and Frame Analysis across the Management and Organizational Literature. The Academy of Management Annals, 8(1): 181-235.

Dahlander, L., \& Frederiksen, L. 2012. The Core and Cosmopolitans: A Relational View of Innovation in User Communities. Organization Science, 23(4): 988-1007.

Davidson, E. 2006. A Technological Frames Perspective on Information Technology and Organizational Change. The Journal of Applied Behavioral Science, 42(1): 23-39.

Davidson, E., \& Vaast, E. 2009. Tech talk: An investigation of blogging in technology innovation discourse. IEEE Transactions on professional communication, 52(1): 40-60.

DaringFireball. 2015. Live From WWDC 2015, With Special Guest Phil Schiller. http://daringfireball.net/thetalkshow/2015/06/09/ep-123. First accessed June 2015.

DiFonzo, N., \& Bordia, P. 2000. How top PR professionals handle hearsay: corporate rumors, their effects, and strategies to manage them. Public Relations Review, 26(2): 173-190.

DiFonzo, N., Bourgeois, M. J., Suls, J., Homan, C., Stupak, N., Brooks, B. P., Ross, D. S., \& Bordia, P. 2013. Rumor clustering, consensus, and polarization: Dynamic social impact and self-organization of hearsay. Journal of Experimental Social Psychology, 49(3): 378-399.

Droge, C., Stanko, M. A., \& Pollitte, W. A. 2010. Lead Users and Early Adopters on the Web: The Role of New Technology Product Blogs. Journal of Product Innovation Management, 27(1): 66-82.

Etter, M., Ravasi, D., \& Colleoni, E. 2018. Social Media and the Formation of Organizational Reputation. Academy of Management Review, in press

Edy, J. A., \& Risley Baird, E. E. 2016. Rumor Communities: The Social Dimensions of Internet Political Misperceptions. Social Science Quarterly, 97(3): 588-602.

Faraj, S., Jarvenpaa, S. L., \& Majchrzak, A. 2011. Knowledge collaboration in online communities. Organization Science, 22(5): 1224-1239.

Faraj, S., von Krogh, G., Monteiro, E., \& Lakhani, K. R. 2017. Online Community as Space for Knowledge Flows. Information Systems Research, 27(4): 668-684.

Faulkner, P., \& Runde, J. 2009. On the Identity of Technological Objects and User Innovations in Function. Academy of Management Review, 34(3): 442-462.

Fine, G. A. 2007. Rumor, Trust and Civil Society: Collective Memory and Cultures of Judgment. Diogenes, 54(1): 5-18.

Fine, G. A., \& DiFonzo, N. 2011. Uncertain Knowledge. Contexts, 10(3): 16-21.

Fine, G. A., \& Khawaja, I. 2005. Celebrating Arabs and Grateful Terrorists: Rumor and the Politics of Plausibility. In G. A. Fine, V. Campion-Vincent, \& C. Heath (Eds.), Rumor 
Mills: The Social Impact of Rumor and Legend: 189-205. New Brunswick, NJ: Transaction Publishers.

Fine, G. A., \& Turner, P. A. 2001. Whispers on the color line. Berkeley, CA: University of California Press.

Fisher, D. G. 2018. Online Communities and Firm Advantages. Academy of Management Review, Available online: https://journals.aom.org/doi/abs/10.5465/amr.2015.0290

Furnari, S. 2014. Interstitial Spaces: Microinteraction Settings and the Genesis of New Practices Between Institutional Fields. Academy of Management Review, 39(4): 439-462.

Gavetti, G., Levinthal, D. A., \& Rivkin, J. W. 2005. Strategy making in novel and complex worlds: the power of analogy. Strategic Management Journal, 26(8): 691-712.

Gioia, D. A., \& Chittipeddi, K. 1991. Sensemaking and sensegiving in strategic change initiation. Strategic management journal, 12(6): 433-448.

Glaser, V. L., Fiss, P. C., \& Kennedy, M. T. 2016. Making Snowflakes Like Stocks: Stretching, Bending, and Positioning to Make Financial Market Analogies Work in Online Advertising. Organization Science, 27(4): 1029-1048.

Granqvist, N., Grodal, S., \& Woolley, J. L. 2012. Hedging Your Bets: Explaining Executives' Market Labeling Strategies in Nanotechnology. Organization Science, 24(2): 395-413.

Grodal, S., Gotsopoulos, A., \& Suarez, F. F. 2015. The Coevolution of Technologies and Categories During Industry Emergence. Academy of Management Review, 40(3): 423-445.

Hannah, D. R., McCarthy, I. P., \& Kietzmann, J. 2015. We're leaking, and everything's fine: How and why companies deliberately leak secrets. Business Horizons, 58(6): 659-667.

Hannigan, T. R., Seidel, V. P., \& Yakis-Douglas, B. 2018. Product innovation rumors as forms of open innovation. Research Policy, 47(5): 953-964.

Hargadon, A. B., \& Douglas, Y. 2001. When Innovations Meet Institutions: Edison and the Design of the Electric Light. Administrative Science Quarterly, 46(3): 476-501.

Hargadon, A. B., \& Sutton, R. I. 1997. Technology Brokering and Innovation in a Product Development Firm. Administrative Science Quarterly, 42(4): 716-749.

Harvey, S. 2014. Creative Synthesis: Exploring the Process of Extraordinary Group Creativity. Academy of Management Review, 39(3): 324-343.

Hayek, F. A. 1978. Competition as Discovery Procedure. In New Studies in Philosophy, Politics, Economics and the History of Ideas: 179-190. London: Routledge.

Houmanfar, R., \& Johnson, R. 2004. Organizational implications of gossip and rumor. Journal of Organizational Behavior, 23: 117-138.

Hsu, G., \& Hannan, M. T. 2005. Identities, Genres, and Organizational Forms. Organization Science, 16(5): 474-490.

Jeppesen, L. B., \& Frederiksen, L. 2006. Why Do Users Contribute to Firm-Hosted User Communities? The Case of Computer-Controlled Music Instruments. Organization Science, 17(1): 45-63. 
Kapferer, J. N. 1990. Rumors: Uses, interpretations, and images. New Brunswick, NJ: Transaction Publishers.

Kaplan, S. 2008. Framing Contests: Strategy Making Under Uncertainty. Organization Science, 19(5): 729-752.

Kaplan, S., \& Tripsas, M. 2008. Thinking about technology: Applying a cognitive lens to technical change. Research Policy, 37(5): 790-805.

Kawachi, K., Seki, M., Yoshida, H., Otake, Y., Warashina, K., Ueda, H. 2008. A rumor transmission model with various contact interactions. Journal of Theoretical Biology, 253(1): 55-60.

Kennedy, M. T. 2008. Getting Counted: Markets, Media, and Reality. American Sociological Review, 73(2): 270-295.

Kennedy, M. T., \& Fiss, P. C. 2013. An Ontological Turn in Categories Research: From Standards of Legitimacy to Evidence of Actuality. Journal of Management Studies, 50(6): 1138-1154.

Khaire, M., \& Wadhwani, R. D. 2010. Changing Landscapes: The Construction of Meaning and Value in a New Market Category-Modern Indian Art. Academy of Management Journal, 53(6): 1281-1304.

Kimmel, A. J. 2004. Rumors and Rumor Control. Mahwah, NJ: Routledge.

Kirsch, D., Moeen, M., \& Wadhwani, R. D. 2014. Historicism and Industry Emergence. In M. Bucheli \& R. D. Wadhwani (Eds.), Organizations in Time: 217-240. Oxford, UK: Oxford University Press.

Lakhani, K. R., \& Wolf, R. G. 2005. Why hackers do what they do: Understanding motivation and effort in Free/Open Source Software Projects. In J. Feller, B. Fitzgerald, S. Hissam, \& K. R. Lakhani (Eds.), Perspectives on Free and Open Source Software: 3-22. Cambridge, MA: MIT Press.

Langner, B., \& Seidel, V. P. 2015. Sustaining the Flow of External Ideas: The Role of Dual Social Identity across Communities and Organizations. Journal of Product Innovation Management, 32(4): 522-538.

Leonardi, P. M. 2011. Innovation Blindness: Culture, Frames, and Cross-Boundary Problem Construction in the Development of New Technology Concepts. Organization Science, 22(2): 347-369.

Leonardi, P. M., \& Vaast, E. 2017. Social Media and Their Affordances for Organizing: A Review and Agenda for Research. The Academy of Management Annals, 11(1): 150-188.

Leonardi, P. M., Huysman, M., \& Steinfield, C. 2013. Enterprise Social Media: Definition, History, and Prospects for the Study of Social Technologies in Organizations. Journal of Computer Mediated Communication, 19(1): 1-19.

Mazmanian, M. 2013. Avoiding the Trap of Constant Connectivity: When Congruent Frames Allow for Heterogeneous Practices. Academy of Management Journal, 56(5): 1225-1250. 
McFarland, L.A. \& Ployhart, R.E. 2015. Social media: A contextual framework to guide research and practice. Journal of Applied Psychology 100, 1653-1677.

McLure Wasko, M., \& Faraj, S. 2000. "It is what one does": why people participate and help others in electronic communities of practice. The Journal of Strategic Information Systems, 9(2): 155-173.

Mische, A. 2009. Partisan Publics: Communication and Contention across Brazilian Youth Activist Networks (Princeton Studies in Cultural Sociology). Princeton, NJ: Princeton University Press.

Muniz, A. M., Jr, \& O'Guinn, T. C. 2001. Brand Community. Journal of Consumer Research, 27(4): 412-432.

Muniz, A. M., Jr, O'Guinn, T. C., \& Fine, G. A. 2006. Rumor in brand community. In D. A. Hantula (Ed.), Advances in social organizational psychology: 227-247. Mahwah, NJ: Erlbaum.

Navis, C., \& Glynn, M. A. 2010. How New Market Categories Emerge: Temporal Dynamics of Legitimacy, Identity, and Entrepreneurship in Satellite Radio, 1990-2005. Administrative Science Quarterly, 55(3): 439-471.

Nelson, R. R., \& Winter, S. 1982. An Evolutionary Theory of Economic Change. Cambridge, MA: Belknap Press of Harvard University Press.

O'Mahony, S., \& Ferraro, F. 2007. The Emergence of Governance in an Open Source Community. Academy of Management Journal, 50(5): 1079-1106.

Oh, O., Agrawal, M., \& Rao, H. 2013. Community Intelligence and Social Media Services: A Rumor Theoretic Analysis of Tweets During Social Crises. MIS quarterly, 37(2): 407-426.

Orlikowski, W. J., \& Gash, D. 1994. Technological frames: making sense of information technology in organizations. ACM Transactions on Information Systems (TOIS), 12(2): 174-207.

Pinch, T. J., \& Bijker, W. E. 1984. The Social Construction of Facts and Artefacts: or How the Sociology of Science and the Sociology of Technology might Benefit Each Other. Social Studies of Science, 14(3): 399-441.

Porac, J. F., Thomas, H., \& Baden-Fuller, C. 1989. Competitive Groups as Cognitive Communities: The Case Of Scottish Knitwear Manufacturers*. Journal of Management Studies, 26(4): 397-416.

Porac, J. F., \& Rosa, J. A. 1996. Rivalry, industry models, and the cognitive embeddedness of the comparable firm. In J. E. Button (Ed.), Advances in Strategic Management, 13: 363388 .

Porac, J. F., Ventresca, M. J., \& Mishina, Y. 2002. Interorganizational Cognition and Interpretation. In J. A. C. Baum (Ed.), The Blackwell Companion to Organizations: 579598. London, UK. 
Powell, W. W., \& Colyvas, J. A. 2008. Microfoundations of Institutional Theory. In R. Greenwood, C. Oliver, K. Sahlin, \& R. Suddaby (Eds.), The SAGE Handbook of Organizational Institutionalism: 276-298. London, UK: SAGE Publications Ltd.

Rao, H. 1994. The Social Construction of Reputation: Certification Contests, Legitimation, and the Survival of Organizations in the American Automobile Industry: 1895-1912. Strategic Management Journal, 15(S1): 29-44.

Rao, H., \& Dutta, S. 2012. Free Spaces as Organizational Weapons of the Weak. Administrative Science Quarterly, 57(4): 625-668.

Ren, Y., Kraut, R., \& Kiesler, S. 2007. Applying common identity and bond theory to design of online communities. Organization studies, 28(3): 377-408.

Riedl, C. \& Seidel, V.P. 2018. Learning from Mixed Signals in Online Innovation Communities. Organization Science. Articles in Advance.

Rindova, V. P., \& Petkova, A. P. 2007. When Is a New Thing a Good Thing? Technological Change, Product Form Design, and Perceptions of Value for Product Innovations. Organization Science, 18(2): 217-232.

Rosa, J. A., Porac, J. F., Runser-Spanjol, J., \& Saxon, M. S. 1999. Sociocognitive Dynamics in a Product Market. Journal of Marketing, 63: 64-77.

Seidel, M.-D. L., \& Stewart, K. J. 2011. An Initial Description of the C-Form. In Research in the Sociology of Organizations, vol. 33: 37-72-72. Emerald Group Publishing Limited.

Seidel, V. P., \& Langner, B. 2015. Using an online community for vehicle design: project variety and motivations to participate. Industrial and Corporate Change, 24(3): 1-19.

Seidel, V. P., \& O'Mahony, S. 2014. Managing the Repertoire: Stories, Metaphors, Prototypes, and Concept Coherence in Product Innovation. Organization Science, 25(3): 691-712.

Seong, S. 2017. A Theory of Crowds in Time and Space: Explaining the Cognitive Foundations of a New Market. In Research in the Sociology of Organizations, 50: 223-252. Emerald Publishing Limited.

Shibutani, T. 1966. Improvised news: a sociological study of rumor. Indianapolis: The BobbsMerrill Company Inc.

Simakova, E., \& Neyland, D. 2008. Marketing mobile futures: assembling constituencies and creating compelling stories for an emerging technology. Marketing Theory, 8(1): 91-116.

Suarez, F. F., Grodal, S., \& Gotsopoulos, A. 2015. Perfect timing? Dominant category, dominant design, and the window of opportunity for firm entry. Strategic Management Journal, 36(3): 437-448.

Sunstein, C. R. 2009. On rumors: how falsehoods spread, why we believe them, what can be done. New York, NY: Farrar, Straus and Giroux.

Tannen, D. 1979. What's in a frame? Surface evidence for underlying expectations. In R. O. Freedle (Ed.), New directions in discourse processing: 137-18. Norwood, NJ: Ablex. 
Taylor, A. 2010. The Next Generation: Technology Adoption and Integration Through Internal Competition in New Product Development. Organization Science, 21(1): 23-41.

Treem, J. W., Dailey, S. L., Pierce, C. S., \& Leonardi, P. M. 2015. Bringing Technological Frames to Work: How Previous Experince with Social Media Shapes the Technology's Meaning in an Organization. Journal of Communication, 65(2): 396-422.

Tripsas, M., \& Gavetti, G. 2000. Capabilities, Cognition, and Inertia: Evidence from Digital Imaging. Strategic Management Journal, 21(10/11): 1147-1161.

Tushman, M. L., \& Rosenkopf, L. 1992. Organizational determinants of technological-changetoward a sociology of technological evolution. Research in Organizational Behavior, 14: 311-347.

Vaast, E., Davidson, E. J., \& Mattson, T. 2013. Talking about Technology: The Emergence of a New Actor Category Through New Media. MIS Quarterly, 37(4).

Veil, S. R., Sellnow, T. L., \& Petrun, E. L. 2011. Hoaxes and the Paradoxical Challenges of Restoring Legitimacy: Dominos' Response to Its YouTube Crisis. Management Communication Quarterly, 26(2): 322-345.

von Krogh, G. V., Haefliger, S., Spaeth, S., \& Wallin, M. W. 2012. Carrots and rainbows: Motivation and social practice in open source software development. MIS quarterly, 36(2): 649-676.

Vosoughi, S., Roy, D., \& Aral, S. 2018. The spread of true and false news online. Science, 359(6380): 1146-1151.

Weick, K. E. 1995. Sensemaking in Organizations. Thousand Oaks, CA: Sage Publications.

Weick, K. E., Sutcliffe, K. M., \& Obstfeld, D. 2005. Organizing and the Process of Sensemaking. Organization Science, 16(4): 409-421.

Zuckerman, E. W. 1999. The Categorical Imperative: Securities Analysts and the Illegitimacy Discount. American Journal of Sociology, 104(5): 1398-1397. 


\section{TABLES AND FIGURES}

Table 1: Comparing models of how technological frames are shaped during product market evolution

\begin{tabular}{|c|c|c|}
\hline & $\begin{array}{l}\text { Existing models of shaping } \\
\text { technological frames }\end{array}$ & $\begin{array}{l}\text { Elaborated model including online } \\
\text { product rumor communities }\end{array}$ \\
\hline $\begin{array}{l}\text { Locus of shaping } \\
\text { technological } \\
\text { frames }\end{array}$ & $\begin{array}{l}\text { Occurs through interactions between } \\
\text { the producer and consumer (e.g. Clark, } \\
\text { 1985) as well as with traditional media } \\
\text { (e.g. Rosa et al., 1999) }\end{array}$ & $\begin{array}{l}\text { Also includes online product rumor } \\
\text { communities due to social media } \\
\text { affording new opportunities for } \\
\text { debating and updating frames (drawing } \\
\text { from McFarland \& Ployhart, 2015; } \\
\text { Cornelissen \& Werner 2014). }\end{array}$ \\
\hline $\begin{array}{l}\text { Interaction } \\
\text { among } \\
\text { individuals }\end{array}$ & $\begin{array}{l}\text { Lower, as individuals are dispersed } \\
\text { across a market, are subject to status } \\
\text { effects, and access is often through } \\
\text { intermediaries }\end{array}$ & $\begin{array}{l}\text { Higher, characterized by wide access, } \\
\text { anonymity, and interdependence. }\end{array}$ \\
\hline $\begin{array}{l}\text { Aggregation of } \\
\text { past experience }\end{array}$ & $\begin{array}{l}\text { Lower, as learning is confined to } \\
\text { individuals and may be concentrated } \\
\text { among those in traditional media }\end{array}$ & $\begin{array}{c}\text { Higher, as permanence of a written } \\
\text { searchable record is kept across social } \\
\text { media }\end{array}$ \\
\hline Speed of revision & $\begin{array}{l}\text { Lower, as revisions occur only with } \\
\text { each product release or media news } \\
\text { cycle }\end{array}$ & $\begin{array}{l}\text { Higher, characterized by immediate } \\
\text { revision in real-time on social media } \\
\text { platforms }\end{array}$ \\
\hline $\begin{array}{l}\text { Role of } \\
\text { producers }\end{array}$ & $\begin{array}{l}\text { Producers influence technological } \\
\text { frames though "activity planned and } \\
\text { prepared by the corporation" } \\
\text { (Simakova \& Neyland, 2008:100) such } \\
\text { as keynote speeches and product } \\
\text { introductions (e.g. David, 1992). }\end{array}$ & $\begin{array}{l}\text { Producers compete with online product } \\
\text { rumor communities in framing an } \\
\text { understanding of new products }\end{array}$ \\
\hline $\begin{array}{l}\text { Role of } \\
\text { consumers }\end{array}$ & $\begin{array}{l}\text { Consumers influence technological } \\
\text { frames by "sharing solutions to } \\
\text { problems and for exchanging ideas } \\
\text { about innovative ways to use a } \\
\text { technology" (Kaplan \& Tripsas, } \\
\text { 2008:797) }\end{array}$ & $\begin{array}{l}\text { Consumers have increased role as } \\
\text { within product rumor communities } \\
\text { they debate what technological frames } \\
\text { are relevant to forthcoming products }\end{array}$ \\
\hline $\begin{array}{l}\text { Role of } \\
\text { traditional media }\end{array}$ & $\begin{array}{l}\text { Media influence technological frames, } \\
\text { such a by being “editors of product } \\
\text { categories" (Lounsbury \& Rao, 2004) }\end{array}$ & $\begin{array}{l}\text { Traditional media, also drawing on } \\
\text { social media, work alongside product } \\
\text { rumor communities in framing an } \\
\text { emergent understanding of new } \\
\text { products }\end{array}$ \\
\hline
\end{tabular}

Table notes: Social media distinctive characteristics from McFarland \& Ployhart (2015) are underlined. 


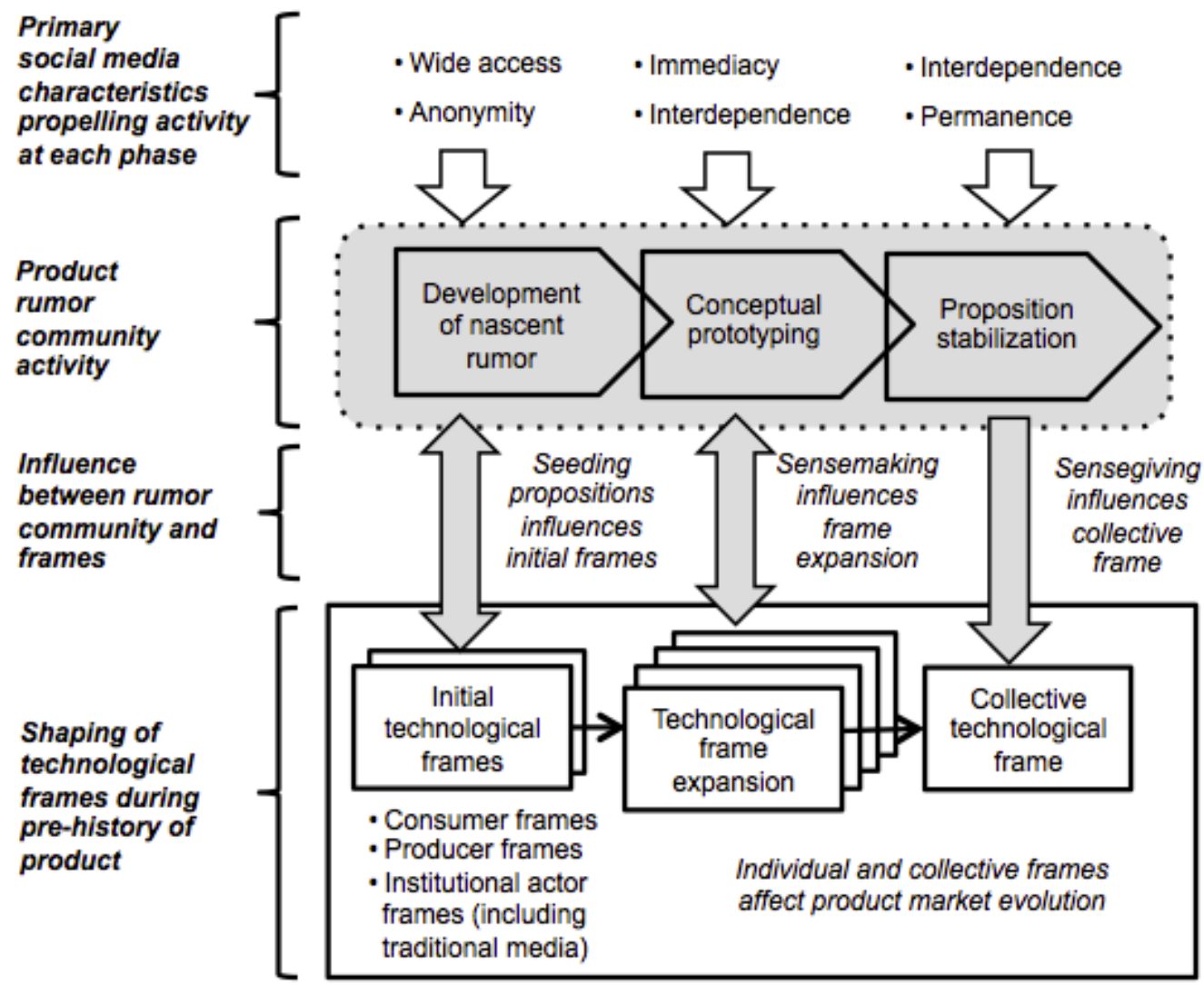

Figure 1: The influence of social media and a product rumor community on technological frames during a rumor life cycle 


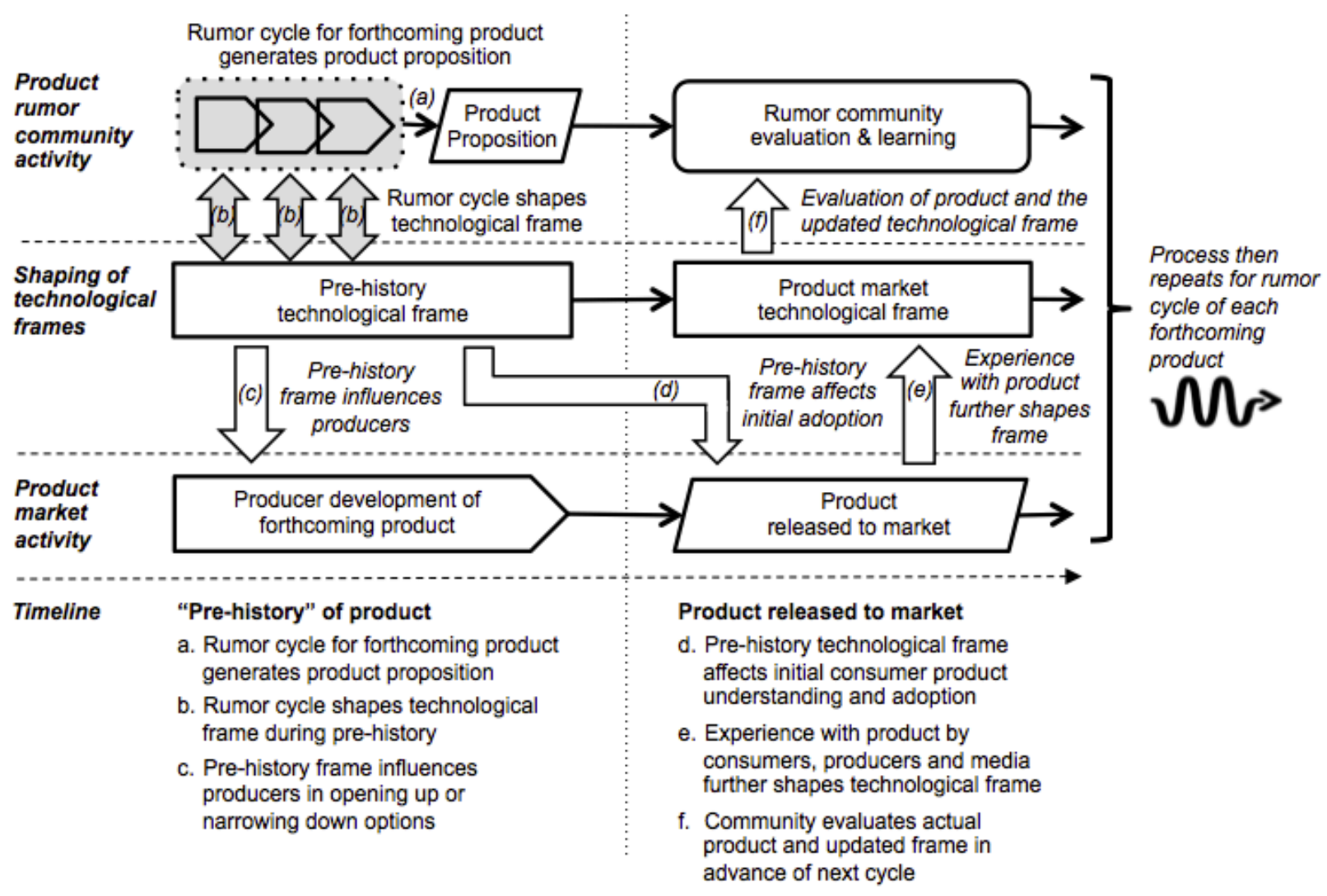

Figure 2: Rumor community activity and technological framing before and after a product is released to market 


\section{Author biographies}

Victor P. Seidel (vseidel@babson.edu) is an associate professor at Babson College, a TECH Innovation Fellow at the Harvard John A. Paulson School of Engineering and Applied Sciences, and a visiting scholar at Said Business School, University of Oxford. His PhD is from Stanford. His research focus is on processes underlying product design evolution across organizations and communities.

Timothy R. Hannigan (tim.hannigan@ualberta.ca) is an assistant professor of Organization Theory and Entrepreneurship at the University of Alberta. He completed doctoral work at the Said Business School, University of Oxford. His research interests cover dynamics in organizational discontinuities-including the contexts of innovation, entrepreneurship, and political scandals.

Nelson Phillips (n.phillips@imperial.ac.uk) is the Abu Dhabi Chamber Chair in Innovation and Strategy at Imperial College Business School in London, UK. Originally from Canada, he completed his $\mathrm{PhD}$ at the University of Alberta. His research focuses on various questions related to innovation and entrepreneurship, often from an institutional theory perspective. 